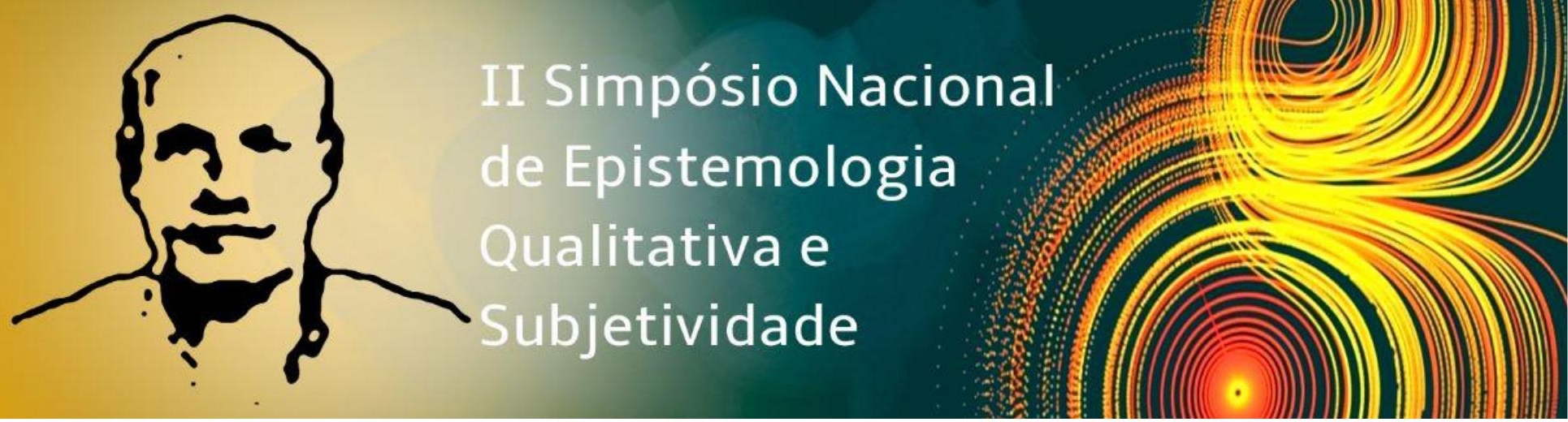

Eixo temático: Teoria da subjetividade: discussões conceituais e relações com outros referenciais teóricos

\title{
REPRESENTAÇÕES SOCIAIS
}

\section{CONFIGURADAS NA SUBJETIVIDADE SOCIAL E SUAS EXPRESSÕES NO TRABALHO PEDAGÓGICO}

\author{
Andreia dos Santos Gomes Vieira, SEEDF/ UnB, andreia.pacp@gmail.com \\ Cristina Massot Madeira Coelho, UnB, cristina.madeira.coelho@gmail.com
}

\section{Resumo}

O presente estudo teve como objetivo geral compreender representações sociais configuradas na subjetividade social de uma escola do Distrito Federal relativas ao trabalho pedagógico. Para tanto, o aporte teórico encontra-se na perspectiva cultural-histórica da subjetividade de Gonzaléz Rey (2015, 2017) conjuntamente com Moscovici (2003) e Jodelet (2017) que nos respaldam nos estudos acerca das representações sociais e Villas Boas (2004) e Sousa (2014) abordando trabalho pedagógico. O percurso epistemológico/metodológico eleito se fundamenta na Metodologia Construtivointerpretativa decorrente da Epistemologia Qualitativa de Gonzaléz Rey. A pesquisa ocorreu entre os anos de 2018 e 2019, em uma instituição da rede pública de ensino, localizada em uma Região Administrativa do Distrito Federal, que atende crianças de 4 e 5 anos na Educação Infantil. Por tratar do trabalho pedagógico realizado pela instituição como um todo, foram colaboradores desta pesquisa diferentes representantes dos segmentos da comunidade escolar. A produção das informações ocorreu por meio de instrumentos variados com o intuito de criar espaços dialógicos favorecedores da expressão do outro, com destaque para as dinâmicas conversacionais. As representações sociais foram compreendidas como produções subjetivas, configurações subjetivas complexas, que integraram elementos subjetivos gerados pelos agentes escolares, protagonistas na produção de representações sociais que caracterizam o trabalho pedagógico da escola. As hipóteses produzidas nos permitiram compreender movimentos singulares presentes na subjetividade social da escola que se expressavam na organização do trabalho pedagógico. A coletividade como um aspecto preponderante da subjetividade social se mostrou favorecedora da produção de configurações subjetivas sociais. As diferentes relações e experiências singulares resultaram em diferentes respostas simbólico-emocionais ao vivido no espaço de convivência comum, que era a escola, corroborando para a construção do modelo teórico que visou integrar no estudo de representações sociais fatos individuais e sociais como sistema único e recursivo, processos afetivos e simbólicos em uma unidade como a definição ontológica de sentidos subjetivos e transcender a associação entre representações sociais e objetos com descrições simples de atributos compartilhados.

Palavras chave: Subjetividade Social. Representações Sociais. Trabalho Pedagógico. 


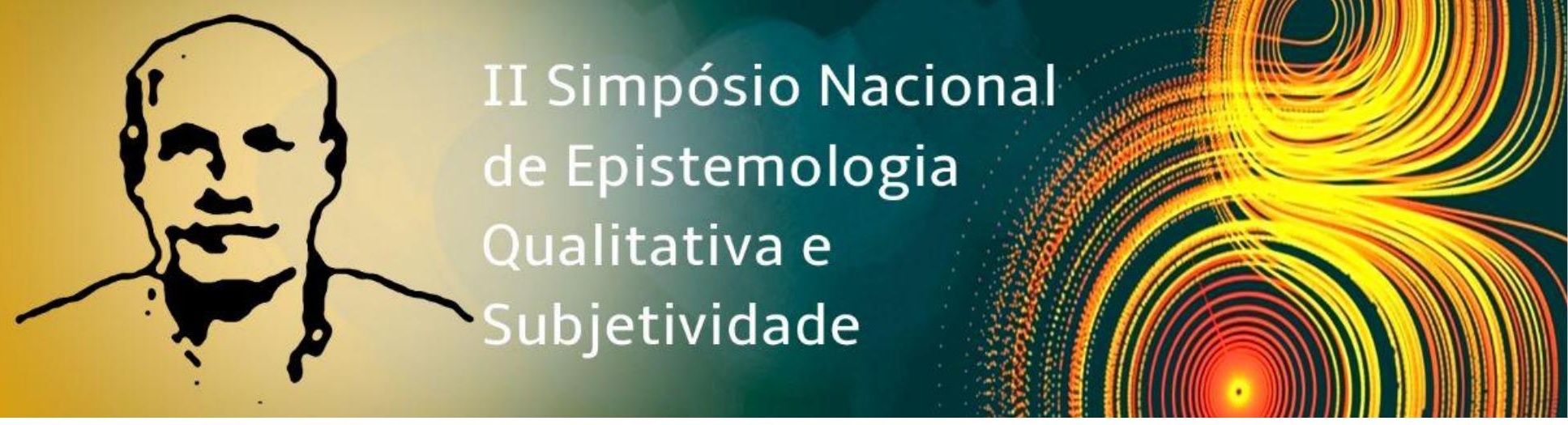

\section{Referências}

GONZÁLEZ REY, Fernando Luis. Subjetividade: teoria, epistemologia e metódo/ Fernando González Rey, Albertina Mitjáns Martínez -- CAmpinas, SP: Editora Alínea, 2017.

A new path for the discussion of Social Representations: advancing the topic of subjectivity from a cultural-historical standpoint. 2015 Disponível em: <https://mail.google.com/mail/u/0/\#search/gonz\%C3\%A1lez+rey/14d81b0e528a476b?projector=1>. Acesso em 20/02/2018

JODELET, Denise $\mathbf{O}$ movimento de retorno ao sujeito e a abordagem das representações sociais. Sociedade e Estado, Brasília, v. 24, n03, p,679-712, set./dez. 2009. Disponível em : < http://www.scielo.br/scielo.php?pid=S0102-69922009000300004\&script=sci_abstract\&tlng=pt $>$ Acesso em: 18/01/2018

MOSCOVICI, Serge. Representações Sociais: investigações em psicologia social./Serge Moscovici;editado em inglês por Gerad Duveen; traduzido do inglês por Pedrinho A. Guareschi. 9 ed. - Petrópolis, RJ: Vozes, 2012

SOUSA, Maria de Fátima Guerra de. Aprendizagem, Desenvolvimento e Trabalho Pedagógico na Educação Infantil: significados e desafios da qualidade. In: TACCA, Maria Carmen (org.). Aprendizagem e Trabalho Pedagógico. 3. ed. Campinas: Alínea, 2014.

VILLAS BOAS, Benigna Maria de Freitas. Tecendo articulações entre portfólio, avaliação e trabalho pedagógico. In: VILLAS BOAS, Benigna Maria de Freitas. Portfólio, avaliação e trabalho pedagógico. Campinas: Papirus, 2004. p. 177-191. 